\title{
NUEVA CULTURA EN LA RESOLUCIÓN DE CONFLICTOS: CONSIDERACIÓN DE DETERMINADAS DEUDAS EN CHILE
}

\section{(NEW CULTURE IN THE CONFLICTS RESOLUTION)}

\author{
ANDRÉS BUSTOS DÍAZ ${ }^{1}$
}

Recibido: 08/04/2019

Aceptado: 27/06/2019

SUMARIO: I. Introducción; II. Métodos alternativos de resolución de conflictos en el derecho chileno.; III. La integración de métodos alternativos de solución de controversias en los procesos judiciales chilenos IV. La situación actual de los tribunales fiscales y aduaneros V. Facultades de los representantes del SII y del SCN en el procedimiento de denuncia seguido por los TTA; VI. Limitaciones a la conciliación en materia fiscal y aduanera. VII. La deuda de los procedimientos ante los tribunales fiscales y aduaneros. VIII. Derecho comparado; IX. Conclusiones; X. Bibliografía.

SUMMARY: I. Introduction; II. Alternative methods of conflict resolution in chilean law.; III. The integration of alternative dispute resolution methods in chilean judicial proceedings; IV. The current status of the tax and customs courts; V. Powers of the representatives of the SII and SNA in the complaint procedure followed by the TTA; VI. Limitations to conciliation in tax and customs matters; VII. The debt of proceedings before the tax and customs courts; VIII. Comparative law; IX. Conclusions; X. Bibliography.

Resumen: El mundo moderno conlleva varios desafíos los cuales el derecho debe dar cuenta para responder de modo adecuado a los diferentes requerimientos actuales. De este modo, el siguiente trabajo tiene por objeto discutir y reflexionar los procesos de resolución de conflictos en nuestro ordenamiento jurídico con detención en el nuevo procedimiento ante los Tribunales Tributarios y Aduaneros. Ello, tomando en cuenta las particularidades que en él se encuentra y el estado actual de los demás procedimientos.

Palabras claves: derecho moderno, conciliación, mediación, tribunales y métodos alternativos de solución de conflictos

\begin{abstract}
The modern world takes some few challenges which the law must estimate to respond appropriate to the different current issues. Thus, the following work aims to discuss and reflect on the processes of conflict resolution in our legal system with detention in the new procedure before the Tax and Customs Courts. This, taking into account the particularities found in it and the current status of the other procedures.
\end{abstract}

Keywords: modern law, conciliation, mediation, courts and alternative dispute resolution methods.

\footnotetext{
${ }^{1}$ Universidad Andrés Bello (Chile)
} 


\section{INTRODUCCIÓN}

Conforme el paso del tiempo, la modernización de los procesos y la sobrecarga de los tribunales en nuestro país, se ha planteado como una forma de descongestión de la judicatura, la incorporación de métodos alternativos de resolución de conflictos en la mayoría de nuestros procedimientos administrativos y judiciales, siendo dentro de los más utilizados por la población la conciliación, la transacción y la mediación.

Desde el año 2000 en adelante, se han dictado diversas leyes que modernizan los procedimientos judiciales en nuestro país, a fin de evolucionar de un mecanismo puramente escrito, como lo es el civil ordinario, a uno donde lo que prime sea la oralidad del mismo, como lo son los procedimientos laborales y de familia.

Pero la modernización no acaba ahí, lentamente se ha ido gestionando instancias de índole administrativa de resolución de conflictos, que, si bien son voluntarias, pasan en ser obligatorias a efectos de la tramitación de un juicio en determinadas materias.

Dicho lo anterior, una de las últimas modificaciones y mejoras es la que se efectuó para los Tribunales Tributarios y Aduaneros, que viene a incorporar mejoras significativas, sin llegar al estándar de la mayoría nacional, esto dado por la diferencia del ámbito del derecho en que se encuentra, el derecho público y en particular, de los impuestos.

El presente trabajo tiene por objeto ilustrar al lector acerca de la realidad jurídica procesal nacional, los mecanismos alternativos de solución de conflictos que hay en ella y abordar ciertas particularidades en las áreas del derecho donde suelen ser más aplicables, para posteriormente detenerse en los procedimientos seguidos ante los Tribunales Tributarios y Aduaneros, para analizar su estado actual en comparativa con lo expuesto.

\section{LOS MÉTODOS ALTERNATIVOS DE RESOLUCIÓN DE CONFLICTOS EN LA LEGISLACIÓN CHILENA}

Desde antaño nuestra legislación ha sido partidaria de adoptar mecanismos alternativos de solución de controversias, que permitan recuperar la paz social que ha sido alterada debido a un conflicto, surgiendo distintas formas a dicho efecto, entre ella la conciliación, como método de solución de controversias de carácter bilateral.

De esta manera, ya en la Constitución de 1823, se encontraba recogida esta institución en su título XV, artículo 1672, estableciéndose en dicho precepto que "ninguna persona podía presentarse a los Tribunales Ordinarios con demanda judicial, sin haber antes concurrido a los de conciliación”. De esta forma, podemos comprender que nuestro derecho reconoce desde sus orígenes a la conciliación como método de resolución de conflicto.

Sin embargo, con la evolución de nuestros cuerpos normativos y modernización de los procedimientos, se han incorporado nuevas materias que deben

\footnotetext{
${ }^{2}$ El artículo 167. de la Constitución de 1823 señalaba que: "Ninguna persona puede presentarse a los Tribunales Ordinarios con demanda judicial, sin haber ocurrido a los de conciliación”. Asimismo, el artículo, 168 de Dicha Carta Fundamental indicaba que: “debe llamarse a conciliación a toda demanda civil y a las criminales que admitan transacción, sin perjuicio de las causas públicas”.
} 
necesariamente ser sometidas a algunas gestiones que tengan por objeto evitar la intervención judicial, aquellas pueden ser judiciales o administrativas y solo una vez agotadas, sin que se llegue a resolver el pleito por esta vía, se podrá continuar con la normal sustanciación de los procesos.

Así las cosas, dada la cualidad que las reviste, esto es, su capacidad de poner término a un proceso, o evitando uno posterior, se les llama habitualmente "equivalentes jurisdiccionales", dado que tienen la misma fuerza que una sentencia judicial, debiendo recurrir a la justicia ordinaria para su cumplimiento compulsivo en la mayoría de los casos.

Dado lo anterior, se hace necesario abordar los equivalentes jurisdiccionales que se hacen presentes en la legislación nacional, así como los procesos en que por disposición normativa se les debe ser aplicable.

\section{La conciliación}

Por conciliación entendemos aquel trámite procesal consistente en el llamado que hace el juez a las partes ${ }^{3}$ del juicio, luego de revisados los antecedentes del caso, para que, de común acuerdo, resuelvan el conflicto, conforme al mérito del proceso hasta ese instante procesal ${ }^{4}$

Dicho lo anterior, podemos señalar que el aludido trámite, tiene como principal característica el ser un mecanismo alternativo y formal de solución de una controversia judicial; en donde la labor del juez corresponde esencialmente en proponer a las partes en conflicto, las bases para un arreglo, debido al mérito de los antecedentes aportados al proceso, teniendo como principal efecto, que sí éstas son aceptadas por los interesados, ponen término anticipado al juicio de forma inmediata.

Ahora bien, la Ley 19.334 de fecha 7 de octubre de 1994, incorporó a nuestro sistema jurídico, el trámite de conciliación de forma obligatoria en todo juicio civil, en que legalmente sea admitida la transacción; ello, a través del artículo 262 (y siguientes) del CPC, excluyéndose para tales efectos, los juicios o procedimientos especiales que tratan los Títulos I, II, III, IV y XVI, del Libro III del CPC. Por consiguiente, y de acuerdo con lo señalado, la conciliación no tendría lugar en los juicios o procedimientos especiales que tratan los Títulos I (juicios ejecutivos por obligación de dar), II (juicio ejecutivo por obligaciones de hacer y no hacer) III, (derecho legal de retención), V (citación de evicción), y XVI (juicios de hacienda) del Libro III ya referido.

\footnotetext{
${ }^{3}$ Entiéndase por para efectos de este trabajo "Parte", como aquella que interviene en un proceso; ya sea como demandante o demandado en un juicio.

${ }^{4}$ El profesor Juan Colombo define la conciliación como; "un acto jurídico procesal bilateral en virtud del cual las partes, a iniciativa del juez que conoce de un proceso, logra durante su desarrollo ponerle fin por mutuo acuerdo". Asimismo, el profesor Mario Casarino, en su libro, "Manual de Derecho Procesal", define al trámite de conciliación como: "aquella manera de poner término a los juicios civiles, salvo las excepciones legales, mediante el acuerdo directo de las partes, producido debido a proposiciones de base de arreglo formuladas por el Tribunal". Al respecto véase COLOMBO, Juan, "La jurisdicción en el Derecho Chileno", en Homenajes Anales de la Facultad de Ciencias Jurídicas y Sociales, Vol. 8 (№ 8), y CASARINO, Mario (2005): Manual de Derecho Procesal. Civil. Tomo III, (Santiago, Editorial Jurídica, 1968), p. 186.
} 


\section{La transacción}

La transacción se encuentra tratada en los artículos 2446 a 2464 de nuestro Código Civil, que la define como "un contrato en que las partes terminan extrajudicialmente un litigio pendiente, o precaven un litigio eventual”. Agrega el artículo en comento además que "no es transacción el acto que sólo consiste en la renuncia de un derecho que no se disputa”. Sin embargo, dicha definición legal no agrega las concesiones recíprocas que deben realizarse las partes.

A su vez, el artículo 1567 del mismo cuerpo legal, considera la transacción como un modo de extinguir las obligaciones, remitiendo al articulado referido en el párrafo anterior.

Debe agregarse además que, si bien la transacción es un contrato y un modo de extinguir las obligaciones, por su capacidad de terminar un litigio por acuerdo de las partes se le mira como un método de resolución de conflictos, dada su calidad de equivalente jurisdiccional, vale decir, tiene el mismo valor que una sentencia definitiva.

Según dispone la normativa civil, solo podrá transigir la persona capaz de disponer de los objetos comprendidos en la transacción, todo mandatario necesitará poder especial para transigir; en el caso del mandato judicial, se trata de aquel poder denominado amplio, que según dispone el artículo $7^{\circ}$ del Código de Procedimiento Civil, requiere mención expresa.

Como se puede apreciar, se trata de un contrato que las partes pueden celebrar y negociar sin asistencia alguna, se trata entonces de una forma no asistida de terminar un conflicto, en qué, si se da en contexto de un juicio, la práctica habitual es estipular que las partes no reconocen los hechos que indica la otra y que el referido contrato solo se celebra con el fin de terminar un litigio, o bien, precaviendo uno eventual, señalando que los contratantes nada se deben.

\section{La mediación}

Podemos entender la mediación como "un sistema de resolución de conflictos en el que un tercero imparcial, sin poder decisorio, llamado mediador, ayuda a las partes a buscar por sí mismas una solución al conflicto y sus efectos” ${ }^{5}$

El artículo 43 de la ley 19.966, establece la primera y única definición legal de mediación que conoce el ordenamiento jurídico chileno ${ }^{6}$ y la define como "un procedimiento no adversarial y tiene por objetivo propender a que, mediante la comunicación directa entre las partes y con intervención de un mediador, ellas lleguen a una solución extrajudicial de la controversia”.

Según veremos más adelante, la mediación forma parte importante de la nueva cultura en la resolución de conflictos, dada su integración a los variados procedimientos administrativos previos a la interposición de acciones judiciales.

Nuestro ordenamiento jurídico, en las leyes $\mathrm{N}^{\circ} 19.966$ del año 2004 y $\mathrm{N}^{\circ}$ 19.966 del año 2005, han establecido las bases de la mediación en los procedimientos

\footnotetext{
5 Sistema Nacional de Mediación Familiar. ¿Qué es la mediación? Obtenido de http://www.mediacionchile.cl/sitioumed/trabajadores. (Consultado el día 28/05/2019)

6 JEQUIER LEHUEDÉ, Eduardo. (2016). La mediación como alternativa de solución de los conflictos empresariales en Chile: Razones y mecanismos para su regulación. Revista de derecho (Valdivia), 29(1), 91-118. https://dx.doi.org/10.4067/S0718-09502016000100005
} 
actuales, con los aprendizajes que se obtuvieron de la iniciativa por integrar la mediación en materia laboral tiempo atrás.

La ley $\mathrm{N}^{\circ} 19.968$ antes mencionada, va un paso más adelante y establece además principios que rigen la mediación en materia de familia, como son: igualdad, voluntariedad, confidencialidad, imparcialidad, el interés superior del niño y la información de terceros.

Actualmente, con la modernización de los procesos administrativos, muchas de las mediaciones que la ley establece se puede solicitar a través de las páginas web de los diferentes organismos administrativos, así, por ejemplo, la mediación en materias de familia y en materia laboral ${ }^{7}$.

Se trata de la forma más accesible a las personas de resolver su conflicto jurídico, sin la necesidad de incurrir en mayores gastos.

\section{Diferencias entre estos métodos}

Atendiendo a la conciliación. Se puede señalar que, a diferencia de la transacción, tiene como característica que las primeras bases de acuerdo son establecidas por el juez. Se trata entonces de un criterio de un tercero ajeno, imparcial según los antecedentes del proceso- que cumple con otorgar patrones que considera conforme a Derecho y que muchas veces, refleja el porvenir del procedimiento. Mientras que la transacción es simplemente un contrato, en que las partes deben negociar sin asistencia alguna, no existe un tercero que otorgue un criterio de equidad, sino que serán la simple batalla de los intereses contrapuestos de los contratantes, en este caso y como se señalaba, sin aceptar ningún hecho ventilado en un proceso, si existe uno, o dejando constancia de que las partes nada se deben.

En comparación con la mediación, la conciliación supone que el juez entrega solamente bases de acuerdo, sin que sea obligatoria mayor acción que actuar como amigable componedor, sin embargo, en la mediación existe una figura propia, el mediador, que debe asumir un rol activo de en la búsqueda de la solución de un conflicto y que posteriormente debe ser llevada ante tribunales con el fin de aceptarla o rechazarla si existiese alguna disconformidad con las leyes sustantivas.

\section{LA INTEGRACIÓN DE LOS MÉTODOS ALTERNATIVOS DE SOLUCIÓN DE CONFLICTOS EN LOS PROCEDIMIENTOS JUDICIALES CHILENOS}

Como se viene diciendo, los procedimientos judiciales chilenos se han visto expuesto de forma paulatina a cambios en su tramitación, siendo uno de los principales, su mutación, desde un proceso en su mayoría escrito, por otros totalmente orales. No obstante, otro cambio que se ha hecho latente en estos procesos es la incorporación de vías alternativas de soluciones de conflictos, como la mediación previa, obligatoria en ciertas materias, o la incorporación del llamado a conciliación por parte del juez durante la prosecución de un juicio.

Por ello, resulta de importancia ilustrar acerca de cuál es el estado actual de los procesos de mayor aplicación en la realidad nacional y posteriormente dar énfasis en la materia que nos avoca.

\footnotetext{
${ }^{7}$ En materia laboral para que proceda la mediación vínculo laboral se debe encontrar vigente.
} 
A) El estado de los procesos civiles: un procedimiento sin mayores vías alternativas de solución de conflictos

Tratándose de los juicios civiles, cuyo procedimiento es en su inmensa mayoría escrito, la figura de los métodos alternativos de solución de conflictos queda relegada en: a) la figura de la Conciliación, regulada en los artículos 262 y siguientes del Código de Procedimiento Civil o, b) a una eventual transacción a las que lleguen las partes.

Según dispone el cuerpo normativo, una vez agotados los trámites de discusión y, vale decir, una vez que las partes han efectuado los descargos pertinentes, el juez se encuentra obligado a citar a las partes a una audiencia a efectos de buscar soluciones y obrará como amigable componedor, para lo cual la ley le habilita a emitir opinión sin que sus dichos lo inhabiliten para posteriormente conocer la causa, todo esto con el fin de obtener un avenimiento entre los litigantes, salvo ciertas excepciones.

En estos casos, se espera que el mismo juez participe en la búsqueda de la solución del pleito más solo emitiendo criterios o propuestas, lo que sirve como opinión de un tercero ajeno, que muchas veces los contendientes dan gran peso.

Sin embargo, si bien la ley establece la conciliación como obligatoria en la etapa antes mencionada, el inciso final del artículo en comento habilita al juez a que pueda efectuar un nuevo llamado en cualquier momento del juicio, requisito que sea evacuada la contestación de la demanda.

En lo referente a la transacción, como se explicó antes, se trata de un contrato en que las partes, o bien terminan un litigio o precaven uno eventual y son las mismas partes que, sin asistencia administrativa alguna, buscan llegar a una solución del conflicto judicial.

Así las cosas, el año 2004 se dicta la ley º19.966 que establece que, tratándose de responsabilidad civil de los prestadores institucionales públicos o sus funcionarios, como de los prestadores privados, para obtener la reparación de los daños ocasionados en el cumplimiento de sus funciones de otorgamiento de prestaciones de carácter asistencial, será necesaria una mediación previa, la cual tendrá lugar ante el Consejo de Defensa del Estado, si fuese un prestador público, o ante la Superintendencia de Salud, si se tratase de un prestador privado.

B) Materias del derecho de familia: mediación institucionalizada

Como se comentaba anteriormente, los procedimientos judiciales chilenos han experimentado durante los últimos 20 años diversas modificaciones normativas, una de ellas es la introducida por la ley $\mathrm{N}^{\circ} 19.968$, publicada en el Diario Oficial de Chile el día 30 de agosto del año 2004, que crea los Tribunales de Familia.

La ley en comento viene a reemplazar los Juzgados de Letras de Menores y agrupar la competencia de ciertas materias que antes de su entrada en vigor eran de competencia civil, siendo uno de los más relevantes, el divorcio.

Sin mayor retardo, comentamos que, el artículo 106 de la referida ley establece que las causas relativas al derecho de alimentos, cuidado personal y al derecho de los padres e hijos e hijas que vivan separados a mantener una relación directa y regular, aun cuando se deban tratar en el marco de una acción de divorcio o separación judicial, deberán someterse a un procedimiento de mediación previo a la interposición de la demanda. 
Dado lo anterior, de un proceso de mediación previa, se podría evitar la contienda judicial, habida consideración de que la ley establece el Acta de Mediación que se levante del acuerdo como un equivalente jurisdiccional si previamente es enviado al tribunal para que tenga conocimiento de aquél.

Tal se puede advertir, en caso de no mediar acuerdo las partes, la mediación previa que toma la calidad de "frustrada" se ha establecido como un requisito de admisibilidad de las demandas de las materias antes mencionadas, las cuales son, por su cotidianidad, las más numerosas.

Así mismo, se han establecido prohibiciones de mediación para los asuntos relativos el estado civil de las personas, la declaración de interdicción y otros.

Para efectos de concretar lo anterior, existen Centros de Mediación licitados a lo largo del país, en los cuales el procedimiento de mediación es gratuito para las partes que participen en él. Es obligación de cada mediador encontrarse inscrito en los registros públicos que lleva nuestro Poder Judicial.

Sin embargo, nuestro sistema procesal en materia de familia establece un procedimiento ordinario compuesto de dos audiencias, estas son: la audiencia preparatoria y la audiencia de juicio. En conformidad con lo dispuesto por el artículo 61, número 5) de la ley $\mathrm{N}^{\circ} 19.968$ se establece que en la audiencia preparatoria se debe "promover, por parte del tribunal, la conciliación total o parcial, conforme a las bases que éste proponga a las partes.”, lo que, en la práctica se suele realizar en ambas audiencias.

\section{C) La situación del derecho del trabajo: la mediación y su costumbre}

Otro punto relevante de destacar es la modernización de la justicia en el derecho laboral que, conforme a las tendencias de los procedimientos judiciales, es un procedimiento oral y cuenta con mecanismos alternativos de solución de conflictos de carácter administrativos.

Para nuestro análisis debemos tratar separadamente dos aspectos de esta área del derecho, como primera parte, el derecho individual del trabajo y el derecho colectivo del trabajo. En el primero, la mediación no es obligatoria y no tiene reglas propias, pero el órgano administrativo suele aplicar las formas de la mediación en el ámbito de la segunda, donde la ley si dedica normas especiales.

Respecto de la primera, podemos señalar que en el ámbito del derecho individual del trabajo la situación es algo diferente a la generalidad, la mediación tiene aplicación solo por un aspecto de costumbre-necesidad, puesto que no existe regulación que la requiera como requisito de admisibilidad de las demandas, pero las personas por su conocimiento o cultura en la materia suelen utilizar las facultades que tiene la Dirección del Trabajo, como un organismo fiscalizador y sancionador.

Suele recurrirse al referido órgano cuando se trata de un despido injustificado, haciendo referencia a la falta de los requisitos de los artículos 159.160 y 161, todos del Código del Trabajo, -que no ahondaremos en la presente-. Este mecanismo se pone en marcha cuando una persona considera que ha sido despedida injustificadamente -o sin las formalidades necesarias- y se dirige el referido organismo, presentando una reclamación administrativa, solicitando una mediación para efectos de solucionar las discrepancias surgidas con ocasión del término de la relación laboral, quien cita al ex empleador a efectos de mediar a este respecto. 
Avocándonos al ámbito del derecho colectivo del trabajo, la mediación en estos casos si se encuentra normada en el Código del Trabajo, específicamente en los artículos 344, 351, 374 bis.

La primera de las normas citadas establece la posibilidad de citar a una mediación voluntaria dentro del proceso de la negociación colectiva, la que se realizará ante la Dirección del trabajo, estamos, por ende, frente a una forma administrativa de solución de conflictos.

El artículo 351 Código del Ramo- se trata de un procedimiento de mediación que debe darse según mandato legal en el caso de la negociación colectiva que tiene lugar con ocasión de la determinación de la huelga, sin embargo, no se podría hablar de mediación en sentido propio, pues tiene un plazo legal para su realización.

Además, el artículo 370 del Código del Trabajo establece la posibilidad de mediación ante la Dirección del trabajo, pero respecto de los trabajadores cuyos contratos sean de obra o faena, o de temporada en el contexto, también, de la negociación colectiva, en que se dota al órgano administrativo de "amplias facultades para instarlas a llegar a un acuerdo.

No obstante, lo antes expuesto, existe la figura de la mediación voluntaria, que se puede solicitar ante el órgano administrativo respectivo, esto es, la Dirección del Trabajo, en cualquier momento mientras que la relación laboral se encuentre vigente. Esta también constituye una vía para efectuar reclamaciones individuales y ser sometidas a mediación.

De similares características que el procedimiento ante los Juzgados de Familia, los procesos en materia laboral se sustentan en dos audiencias: la audiencia preparatoria y la audiencia de juicio. En la primera de ellas, conforme al artículo 453 del Código del Trabajo, el juez, una vez terminada la etapa de discusión debe llamar a las partes a conciliación, proponer bases de acuerdo, sin que sus opiniones lo inhabiliten para dictar sentencia.

D) La nueva cultura de la resolución de conflictos en el derecho público

Hasta ahora hemos dado conocimiento al lector de los procedimientos judiciales chilenos y cómo estos han incorporado sistemas alternativos de resolución de conflictos en materias de Derecho Privado. Una vez resuelto lo anterior, toca abordar este tema desde otro ámbito del derecho, éste es, desde la perspectiva del Derecho Público con sus respectivas particularidades.

Existen bastantes diferencias entre los diferentes ámbitos del derecho, así, en materia de derecho privado rige la máxima que señala que las personas podrán hacer todo aquello que la ley no les prohíba, lo que es llamado comúnmente como su "regla de oro del derecho privado”.

En el Derecho Público, la situación es diversa, dado que esta regla se invierte, ya que las personas solo podrán hacer aquello que la ley les permite. Esta consagración tiene un reconocimiento constitucional dado por el artículo $7^{\circ}$ de nuestra Constitución Política de la República, que establece que "Ninguna magistratura, ninguna persona ni grupo de personas pueden atribuirse, ni aun a pretexto de circunstancias extraordinarias, otra autoridad o derechos que los que expresamente se les hayan conferido en virtud de la Constitución o las leyes”

Ya en el ámbito de nuestra investigación, para participar en estos métodos alternativos de resolución de conflictos será necesaria una habilitación expresa, que esté 
dada por algún cuerpo normativo, por lo que nos referiremos a ellos en los procedimientos llevados ante los Tribunales Tributarios y Aduaneros.

\section{EL ESTADO ACTUAL DE LOS TRIBUNALES TRIBUTARIOS Y ADUANEROS (TTA)}

Como resulta lógico, los Tribunales Tributarios y Aduaneros tiene la competencia de estas dos materias, por lo que nuestro trabajo abordará separadamente estos procedimientos, los cuales se han visto sucesivamente modernizados, incorporando esta nueva cultura de la resolución de conflictos.

\section{Moderna justicia tributaria}

El artículo 155 del Código Tributario entrega expresamente la competencia a los tribunales ya referidos en materias de reclamaciones tributarias y de las denuncias por infracción a las disposiciones tributarias.

Uno de los elementos esenciales en materia de conciliación es la disponibilidad de los intereses discutidos, en atención a ello, es necesario establecer dicha situación en razón a los presupuestos que conforman o integran la obligación tributaria.

Podemos definir a la obligación tributaria como aquel: "vínculo jurídico, cuya fuente inmediata es la Ley, que nace con motivo de ocurrir los hechos o circunstancias que la misma normativa señala, y en cuya virtud personas determinadas deben entregar al Fisco, sumas también determinadas en dinero, para la satisfacción de las necesidades Públicas y Colectivas".

En atención a lo anterior, para que un hecho o acontecimiento sea considerado como hecho imponible, éste debe corresponder íntegramente a lo previsto en la normativa en cuestión, es decir, el hecho económico acontecido debe coincidir perfectamente con los presupuestos legales, teniendo como consecuencia que, si estos calzan, se genera el vínculo obligacional; esto es, la ocurrencia del hecho imponible.

Ahora bien, uno de los elementos fundamentales de la obligación tributaria es su “determinación”, la cual no es otra cosa que establecer en cada caso particular la configuración del presupuesto de hecho y el alcance de este. En tal sentido, hacemos alusión al considerando "Quinto" de la resolución No 22849 de la Excelentísima Corte Suprema de Chile, del 30 de Diciembre del año 2003, el cual de forma clara y precisa señala que "la obligación tributaria nace por el solo ministerio de la Ley; no obstante a condición de que acontezcan los hechos previstos en ella, como aptos para darle nacimiento; si tales hechos no acaecen, por reprochable que sean la conducta del contribuyente, no puede nacer a la vida jurídica la obligación tributaria”. En consecuencia, podemos señalar que la determinación de la obligación tributaria tiene un efecto declarativo, en atención a la carga impositiva establecida por Ley.

Por otra parte, una vez finalizado el proceso de “determinación”, procede la etapa de "liquidación", la cual tiene por finalidad cuantificar en dinero el tributo ya declarado, es decir, sellar el monto o suma a pagar por parte del contribuyente.

Por consiguiente, en el caso de que exista discrepancia entre la administración y el contribuyente, en virtud de la ocurrencia de un presupuesto de hecho o de la deuda líquida exigible resultante de la realización del hecho imponible, mientras no exista una 
sentencia firme y ejecutoriada que establezca y determine lo ya señalado, los intereses discutidos son plenamente disponibles para las partes intervinientes.

En tal orden de ideas, no se trata de discutir la noción de potestad tributaria que descansa en manos del Estado; sino más bien que, "mediante el ejercicio de unas potestades que le son plenas, la administración tributaria puede llegar a conciliar con los administrados en algunos elementos que se manejan a partir de la obligación tributaria definida en la Ley".

En suma, los intereses en conflicto en materia tributaria pueden disponerse y, por ende, ser susceptible de consenso, mientras se discuta la determinación de la obligación tributaria o la liquidación de la misma; es decir, que sea susceptible de algún tipo de acción por vía administrativa o judicial, en razón a una sanción por incumplimiento.

Conforme a la evolución de los procesos, la ley $N^{\circ} 21.039$ del año 2017, que perfecciona la justicia tributaria y aduanera, dictada el año 2017, incorpora al procedimiento la conciliación en materia tributaria al procedimiento general de reclamación de los tributos, sumando este procedimiento a la regla general de nuestro ordenamiento jurídico en donde todos aquellos contemplan al menos la posibilidad de conciliar en juicio, ya sea a solicitud de parte o, de oficio, por el tribunal; así lo establece el artículo 132 del Código del Ramo.

No obstante, no podemos dejar de mencionar que esta conciliación tiene ciertos límites, pues conforme a lo dispuesto por el artículo 132 bis del Código Tributario, no podrá ser la simple disminución de los impuestos adeudados, salvo a) cuando esta se fundamente en la existencia de errores de hecho o de derecho, b) los antecedentes no permitan concluir la concurrencia de los hechos gravados, c) los impuestos resulten ser excesivos conforme a los antecedentes tenidos a la vista en la causa.

Así las cosas, este llamado a conciliación no procederá en los procedimientos establecidos por los artículos $4^{\circ}$ quinquies, 100 bis, 160 bis, 161 y 165, todos del Código Tributario, en atención a su calidad de delitos tributarios como el abuso o simulación tributaria. Así, la conciliación se incorpora en uno de los procedimientos más comunes del procedimiento llevado en estos tribunales.

\section{La modernización en materia de derecho aduanero}

Bajo los efectos de las modificaciones sufridas por la ley $\mathrm{N}^{\circ} 21.039$ del año 2017 y al igual que en materia tributaria, el procedimiento de aplicación general en materias ve incorporado en su normativa la necesidad de una mediación durante el proceso.

Así, se establece en el artículo 128 de la ley 20.322 que el juez, de oficio o a petición de parte, debe llamar a las partes a una audiencia de conciliación una vez terminada la etapa de discusión -siguiendo las mismas reglas del proceso civil ordinario-.

La forma en que se lleva a cabo la conciliación está determinada por el artículo 128 bis del mismo cuerpo legal, que establece que solo se podrá conciliar respecto de: a) la existencia de los elementos que determinan el nacimiento de la obligación tributario aduanera, su cuantía o el monto de los derechos, impuestos o multas determinados, b) la calificación jurídica de los hechos conforme a los antecedentes aportados en el procedimiento, la ponderación o valoración de las pruebas 
respectivas y, c) la existencia de los vicios o errores manifiestos de legalidad, ya sea de forma o de fondo, siempre que todo lo anterior haya sido alegado expresamente en el reclamo o se trate de casos en que el Tribunal pueda pronunciarse de oficio.

De la misma manera que en materia tributaria, existe prohibición de que la conciliación consista en la "mera disminución del monto del o los derechos aduaneros o impuestos adeudados, salvo cuando ello se funde en la existencia de errores de hecho o de derecho en su determinación, o en antecedentes que permitan concluir que no concurren los elementos del hecho gravado establecido en la ley o cuando los impuestos determinados resulten ser excesivos conforme a los demás antecedentes tenidos a la vista con motivo de la conciliación.” Así lo dispone el artículo 128 bis de la ley del ramo.

\section{PODERES O FACULTADES DE LOS REPRESENTANTES DEL SII y SNA EN EL PROCEDIMIENTO DE RECLAMACIÓN SEGUIDO ANTE LOS TTA}

Teniendo claro que el juez del TTA se encuentra facultado para proponer a las partes del juicio, eventuales bases de acuerdo en el procedimiento de reclamación ya aludido, es necesario referirnos a las facultades de las partes para poder aceptar las bases de acuerdo propuestas por el juez del TTA, las cuales, a nuestra consideración, se sustentan en las potestades legales y reglamentarias que la propia Ley les otorga a los Directores Regionales de SII, SNA y a los Administradores de Aduana.

\section{Facultades que permiten conciliar a los directores regionales del SII}

Actualmente el SII, mantiene vigente el "procedimiento administrativo de revisión de la actuación fiscalizadora”, el cual fue creado por la Circular N. ${ }^{\circ}$ 57, del 21 de septiembre de 2000. Dicho procedimiento, tiene por finalidad otorgar una instancia de revisión administrativa de los actos realizados por los fiscalizadores del SII, tanto en sus aspectos formales como del fondo, evitando así, la comparecencia innecesaria del contribuyente ante el Tribunal Tributario, pudiendo éste, previo a ejercer una acción judicial, solicitar a la autoridad administrativa que dictó el acto que se impugna, la revisión de todos los vicios o errores de legalidad en que haya incurrido el SII en su labor fiscalizadora. De este modo, el Director Regional podrá dictar una resolución en sede administrativa en la que decida: a) mantener su posición y actuación de forma íntegra; b) establecer que la reclamación del contribuyente sólo es aceptada en parte o; c) acoger la posición del contribuyente en su totalidad, debido a que las actuaciones del fiscalizador del SII adolecían de errores o vicios manifiestos. Esta última alternativa, es un claro ejemplo de que el Director Regional del Servicio cuenta con facultades para dejar sin efecto un acto de fiscalización, aceptando los argumentos del contribuyente.

En el mismo sentido, con la Ley 20.322, comenzó a operar un procedimiento especial llamado "Recurso de Reposición Administrativa", el que ha sido incorporado mediante el artículo 123 bis del CT, cuya finalidad es solucionar de forma ágil, rápida y oportuna, los problemas ocasionados a los contribuyentes, producto de los actos administrativos con que concluye una fiscalización. Con todo, las causales para interponer este recurso son básicamente las mismas que se conceden para la reclamación judicial seguida ante el TTA, esto es, aquellas que permiten impugnar liquidaciones, giros, cobros y resoluciones, que incidan en el pago de un impuesto o en los elementos que sirvan de base para determinarlo. Ahora bien, con el objeto de regular 
la operatoria de este recurso, con fecha 29 de enero del 2010, el Director Nacional del SII, haciendo uso de sus facultades interpretativas, dictó la Circular $\mathrm{N}^{0} 13$, la que tiene por finalidad impartir las instrucciones necesarias para la aplicación práctica del nuevo artículo 123 bis de CT, en donde se incorporó una "audiencia de conciliación”, la cual puede ser decretada a petición del contribuyente o de oficio por el propio Director Regional del SII. Así, este trámite tiene como principal efecto, acercar las posiciones del contribuyente con el ente fiscalizador, pudiendo el primero, presentar declaraciones rectificatorias de impuestos, de suerte que, el Director Regional, en caso de que exista acuerdo en la audiencia de conciliación, dar por terminada la reclamación, acogiendo administrativamente los argumentos y defensas del contribuyente.

Artículo 127 del CT: El precepto referido, otorga al contribuyente el derecho para que, de forma conjunta a la reclamación, impugne la nueva liquidación y solicite la rectificación de cualquier error que adolecieren las declaraciones o pagos de impuestos correspondientes al período reliquidado. De cualquier modo, esto implica que las solicitudes de rectificación de errores propios serán resueltas en la misma sentencia definitiva de primera instancia en que se falle el reclamo respectivo. De lo anterior debemos tener claro, en definitiva, que las solicitudes de rectificación que se presenten con anterioridad al inicio del procedimiento de reclamación serán resueltas por el Director Regional competente, y éste contará con todas y cada una de las facultades legales del caso para acogerlas o aceptarlas. En tal sentido, cabe preguntarse, ¿bajo qué argumento el Director Regional en un llamado a conciliar no podrá concordar o consentir, en dicho momento, en aceptar o acoger las solicitudes de errores propios?

En conclusión, y razonando lógicamente, no cabe duda de que, si el Director Regional se encuentra facultado para resolver en uso de sus facultades, todos los asuntos de carácter tributario que se promuevan en sede administrativa, incluyendo el recurso de reposición. En este sentido, no parecería razonable que la misma autoridad en sede judicial, no pueda hacer valer aquellas facultades frente a un llamado a conciliar hecho por el juez del TTA, a fin de solucionar de forma eficaz el asunto en cuestión, ya que tal actuación produce innegablemente el mismo efecto que el generado en el procedimiento administrativo, esto es, poner fin la impugnación interpuesta por el contribuyente de forma inmediata.

\section{Facultades que permiten conciliar a los directores regionales y administradores del SNA}

Como es sabido, tanto la Ordenanza de Aduanas, como la Ley Orgánica del Servicio Nacional de Aduanas, le entrega a dicho Servicio, "la fiscalización del paso de las mercancías por las constas, fronteras y aeropuertos de la República”, cuestión que se realiza mediante la aplicación de las normas relativas a la clasificación, valoración, aforo de las mercancías y la determinación del origen de estas, de todas aquellas que ingresan o están de paso en nuestro país.

La Potestad antes mencionada, podrá ser ejercida por el propio director del SNA, o bien, por los Directores Regionales respectivos o los Administradores de Aduana, pudiendo estos a su vez efectuar las liquidaciones o cargos arancelarios o tributarios correspondientes, respecto de las mercancías que ingresen al país desde el extranjero o de zonas de tratamiento aduanero.

Ahora bien, la Ley 20.322, incorporó el artículo 121 a la ORD, estableciendo al igual que en materia tributaria, el denominado "recurso de reposición administrativa", 
cuyo fin es revisar lo resuelto por la autoridad de SNA en relación a) liquidaciones, cargos y actuaciones que sirvan de base para la fijación del monto o determinación de diferencias de derechos, impuestos, tasas o gravámenes; b) la clasificación y/o valoración aduanera; c) declaraciones de exportación, y d) actos o resoluciones que denieguen total o parcialmente las solicitudes efectuadas en conformidad al Título VII del Libro II, (esto se refiere a las devoluciones de gravámenes aduaneros). Dicho recurso, se interpone ante la misma autoridad que dicto el acto que se pretende impugnar, esto es, ante el Director Regional o Administrador de Aduana, según corresponda.

En suma, podemos concluir que los Directores Regionales del SNA, como los Administradores de Aduana, gracias a las facultades que le son otorgadas para poder resolver el recurso de reposición administrativa; es también posible que en el procedimiento de reclamación aludido, la autoridad acepte las bases de acuerdo ante el llamado a conciliación hecho por el juez del TTA, ya que al igual como ya ha sido dicho respecto del SII, tal actuación produce innegablemente el mismo efecto que se genera al aceptar el recurso de reposición acogiendo el planteamiento del contribuyente, esto es, poner fin al procedimiento, de forma inmediata.

\section{LIMITACIONES A LA CONCILIACIÓN EN MATERIA TRIBUTARIA Y ADUANERA}

Como se expuso anteriormente, si bien la ley ha progresivamente incorporado a los procedimientos la conciliación, aquella no puede recaer sobre ciertas materias, que son, en síntesis, la disminución de la carga tributaria que trae aparejado un acto que dé lugar al nacimiento de la obligación tributaria.

Esta prohibición nace del catálogo de Derechos Fundamentales consagrados en el artículo 19 de nuestra Constitución Política de la República, que señala en su numeral 20: "La igual repartición de los tributos en proporción a las rentas o en la progresión o forma que fije la ley, y la igual repartición de las demás cargas públicas.”.

Así, se ha señalado también por la doctrina nacional que:

"La igual repartición de los tributos, que tan categóricamente consagra el $N^{\circ}$ 20 del artículo 19 de la Constitución, es una especie dentro del género de la igualdad ante la ley. $O$ de otra manera, es una especificación en el ámbito de los tributos de la garantía que consagra en el $N^{\circ} 2$ del mismo artículo"8 (La cursiva es nuestra)

Complementando lo anterior, nuestra Carta Magna ha establecido en su artículo 6 el Principio de supremacía constitucional, por el cual todos los órganos del estado deberán actuar conforme a la Constitución, so pena de incurrir en las responsabilidades que por ley se establecen.

Así las cosas, parece del todo acertado que no se podrá conciliar respecto de una rebaja en los tributos que tenga aparejado la concurrencia del hecho gravado de un individuo, ya que se incurriría en una desigualdad ante la ley tributaria y por prohibición constitucional. Lo anterior, sin embargo, no obsta a obtener una rebaja en el pago de la obligación tributaria obtenida a través de la conciliación respecto de los elementos del hecho gravado, habida habilitación expresa que se señaló anteriormente.

\footnotetext{
${ }^{8}$ EVANS, Eugenio: Los tributos en la Constitución, 2da Edición, págs. 105 - 107 (Santiago, Editorial Jurídica de Chile, 2010)
} 


\section{LA DEUDA DE LOS PROCEDIMIENTOS ANTE LOS TRIBUNALES TRIBUTARIOS Y ADUANEROS}

Como se ha ilustrado anteriormente, los procedimientos tributarios $\mathrm{y}$ aduaneros de aplicación general han establecido un momento en que el llamado a conciliación se hace obligatorio, con la posibilidad de conciliar en determinadas materias, con las limitaciones impuestas por la naturaleza misma de los tributos y, en general, del Derecho Público.

Sin embargo, como se ha expuesto anteriormente, en los otros ámbitos del derecho se encuentra un poco más desarrollado la idea de una solución alternativa de conflictos, en los procedimientos de familia la mediación es obligatoria,

En el ámbito laboral la gente, por conocimiento popular recurre a la mediación administrativa en una de las materias más habituales, los despidos injustificados.

También, en materias de responsabilidad en los prestadores de salud, que son de competencia civil ordinaria, se establece la obligación de acudir a una mediación ante diversos organismos administrativos, so pena de no admitir a tramitación la demanda.

Es en este sentido, que la normativa vigente en materia de derecho procesal tributario y aduanero se encuentra muy por debajo del estándar del resto de los procedimientos judiciales -al igual que en materia civil ordinaria-. Por ello, las normas jurídicas que regulan esta materia deberían adaptarse a la mayoría de los procedimientos modernos que existen en el país.

\section{DERECHO COMPARADO}

Como elemento a considerar para efectos del presente análisis, haremos referencia a lo que ocurre en el derecho comparado, especialmente en Estados Unidos, Gran Bretaña, Francia, España, Colombia y Costa Rica, dado que dichos países, en lo que respecta al ámbito tributario, han establecido mecanismos alternativos de solución de controversias; a fin de buscar la rapidez y eficacia, por medio de acuerdos consensuados, en materia de conflictos tributarios y aduaneros.

\section{ESTADOS UNIDOS}

En Estados Unidos, las relaciones tributarias existentes entre el contribuyente y la administración en el Ordenamiento Federal Americano, están asentadas sobre la base de las llamadas Alternative Dispute Resolution, o ADR, las que permiten que en el caso de no llegar a una solución en la negociación administrativa, el contribuyente pueda someter la cuestión controvertida a un tercero entrenado para que actué como mediador, quién a través de su intervención independiente e imparcial, ayudará a encontrar una solución ${ }^{9}$. De esta forma, en dicho país se han creado numerosas agencias, cuya finalidad es servir de "árbitros”, para que, ante posibles conflictos tributarios, el contribuyente no llegue a litigar con la administración ante los Tribunales Tributarios de Estados Unidos o los “tax court”.

\footnotetext{
${ }^{9}$ Esto es lo que el ordenamiento tributario estadounidense denomina la “Fast Track Mediation” o Vía Rápida De Mediación.
} 


\section{GRAN BRETAÑA}

La situación de Gran Bretaña tiene un matiz distinto al de Estados Unidos, pero va en el mismo ya que en el caso de desacuerdo sobre el actuar fiscalizador, antes de recurrir a los Tribunales, existe la posibilidad (vía administrativa) para que los procedimientos tributarios finalicen mediante acuerdo entre la autoridad (Board of Inland Revenue), y el contribuyente. En tal sentido, el agreement puede llegar a favorecer a ambas partes, ya que el contribuyente recibirá un trato más favorable al que hubiese recibido en el procedimiento normal de exigencia de pago mediante la vía contenciosa y, por su parte, el Board of Inland Revenue, se ahorra el trámite de tener que acudir a los Tribunales de Justicia para poder hacer efectivo el pago de la deuda, evitando de este modo, demoras en el cobro efectivo de la misma" ${ }^{10}$.

\section{FRANCIA}

Un caso particular en esta materia es el de Francia, país que ha tratado de aplicar técnicas alternativas de solución de controversias, basándose para ello, principalmente, en la potestad discrecional que posee la autoridad administrativa ${ }^{11}$. E efecto, se introdujo en dicha legislación la figura de los RAD (Reglement Alternatif des Differents), o los MARC (Modes Alternatif de Reglement des Conflicts), que engloban modos diferentes de solución de conflicto a fin de conciliar los intereses de los afectados (contribuyentes y autoridad), mediante una solución equitativa, pero no obligatoria $^{12}$.

Por otra parte, el artículo 247 del Livre des Procédures (libro de los Procedimientos Tributarios), permite reducir los conflictos entre la administración y los ciudadanos, gracias a la condonación total o parcial de las cuotas tributarias derivadas de impuestos directos, sanciones tributarias e intereses de mora; así como la reducción de estas sanciones y gravámenes por medio de la transacción. Sin embargo, para ello, el contribuyente deberá alegar y acreditar ante la administración, indigencia o apuro económico que le impida satisfacer sus responsabilidades tributarias.

\section{ESPAÑA}

En España a través de la figura de las “actas con acuerdos”, se permite, mediante la vía del dialogo, dotar de certeza los asuntos controvertidos que resulten de una comprobación o investigación fiscalizadora para con el contribuyente. En dicha situación, el órgano administrador competente para tramitar un acto de tal naturaleza es el "Inspector Actuario" de cada localidad. De este modo, frente a la existencia de dudas razonables sobre la interpretación de la norma aplicable, o al supuesto de hecho de dificultad para comprobar el monto susceptible de un gravamen, la administración tributaria y el obligado tributario en conjunto, pueden llegar a un acuerdo para

\footnotetext{
${ }^{10}$ CASANELLAS, M. \& OLAY DE PAZ, M, "La revisión de Actos Administrativos y el Régimen Sancionador Tributario en el Reino Unido”, en Quincena Fiscal (No. 12, 2003), p. 45.

${ }^{11}$ GIL, Eva (2009): Las actas con acuerdo en el procedimiento inspector tributarios, (Madrid, Thompson Reuters), p.83.

${ }^{12}$ GIL, Las actas ... p. 84.
} 
determinar el valor final a pagar, así como también, establecer la procedencia o improcedencia de un tributo ${ }^{13}$.

A mayor abundamiento, el artículo 39 del Estatuto de Autonomía del país Vasco, establece la creación de una "comisión arbitral" para posibles conflictos que pudieren suscitarse entre las Instituciones de las Comunidades Autónomas y cada uno de los territorios que las integran, en relación a cuestiones concretas del ámbito tributario. Lo precedentemente dicho, se trata de un arbitraje obligatorio, que excluye la vía judicial sin que las partes hayan manifestado su voluntad en tal sentido y sin que quepa recurso alguno contra el laudo. Lo anterior, demuestra un gran avance en materia de acuerdos tributarios, debido a que específicamente se crea una instancia obligatoria de consenso para el contribuyente y la entidad fiscalizadora, a fin de que puedan resolver las desavenencias promovidas entre ellos.

Cabe agregar que la ley 39/2015 en su artículo 86 permite la terminación convencional de los procedimientos administrativos, por "acuerdos, pactos, convenios o contratos con personas tanto de Derecho público como privado, siempre que no sean contrarios al ordenamiento jurídico ni versen sobre materias no susceptibles de transacción y tengan por objeto satisfacer el interés público que tienen encomendado, con el alcance, efectos y régimen jurídico específico que, en su caso, prevea la disposición que lo regule (...)” Como vemos, de gran utilidad para resolución de los conflictos y que debe ser aprobado por el Consejo de Ministros u órgano equivalente de las Comunidades Autónomas de tal país.

Y en este mismo sentido, la ley 29/1998 en su artículo 77 permite a las partes, una vez realizada la etapa de discusión, que se promueva un acuerdo entre las partes es un equivalente a nuestra figura de la conciliación, salvo que la norma española habilita desde ya a los órganos administrativos que sean demandados a llegar a conciliación mientras tenga la autorización oportuna.

\section{COLOMBIA}

El caso colombiano es algo similar, ya que de conformidad al artículo 147 de la Ley 1607 del año 2012, permitió que el contribuyente y la Dirección de Impuestos y Aduanas, pudieran presentar acuerdos conciliatorios sobre sanciones y determinaciones de impuestos; aun cuando dichos actos administrativos se encontrarán en trámite judicial ante la jurisdicción contenciosa.

Ahora bien, el artículo 3 del Decreto 699 del año 2013, por el cual se reglamentaron los artículos 147 y siguientes de la Ley antes mencionada, estableció como requisitos - entre otros- , que para poder optar a presentar acuerdos conciliatorios sobre sanciones y determinaciones de impuestos, era necesario que con anterioridad al 26 de diciembre del año 2012, se haya presentado demanda de nulidad y

\footnotetext{
${ }^{13}$ Por consiguiente y tal como lo indica el profesor don Luis María Romero, las actas con acuerdo tienen como finalidad: “ evitar un ulterior conflicto jurisdiccional mediante un encuentro dialéctico mantenido entre el obligado tributario y la administración, cuya finalidad es determinar datos o hechos controvertidos respecto a la cuantía exigible y su calificación jurídica, con el objetivo de eliminar de forma concordadas esas dudas que tras aplicar la norma tributaria, hacen que surjan aspectos polémicos del supuesto de hecho o de la valoración tributaria, lo que en definitiva, con la suscripción de un acta con acuerdo, se consigue materializar la intencionalidad que el legislador ha querido establecer en la ley."13 Véase en ROMERO, M.L: Las actas con acuerdo en la Ley General Tributaria y en el derecho comparado, (Toledo, Ediciones Universidad Castilla de -La Mancha, 2010), p. 241.
} 
restablecimiento de derecho contra una serie de supuestos; entre los cuales encuentran las liquidaciones de revisión, de corrección, de aforo, de valores y, las resoluciones que impongan sanciones al contribuyente.

Por otra parte, dicho precepto agregó como requisito adicional, la no existencia de una sentencia definitiva, y que la solicitud de conciliación debía ser presentada hasta el 31 de agosto de $2013^{14}$.

Ante lo expuesto, si bien puede desprenderse que la conciliación tributaria y aduanera en Colombia se encuentra recogida por el legislador, ésta es aplicable sólo para procesos iniciados con anterioridad al 26 de diciembre del año 2012, y con solicitudes de conciliación hasta el 31 de agosto de 2013, cuestión que claramente restringe la procedencia de esta institución a los futuros conflictos tributarios, los que sin duda podrían ser resueltos por esta vía.

\section{COSTA RICA}

Finalmente, el caso de Costa Rica no deja de llamar la atención, ya que su normativa vigente en materia tributaria ha permitido que, mediante interpretaciones doctrinarias, se acepte la conciliación, en el caso de las infracciones administrativas, ya que se ha permitido la procedencia de esta institución en casos relacionados con obligaciones tributarias accesorias, como por ejemplo recargos y multas. Lo anterior siempre y cuando éstas no formen parte del tributo; es decir, de la obligación principal,

Por consiguiente, en tal legislación es viable la conciliación en materia administrativa, ya que ésta se basa sólo en infracciones por incumplimiento anexos a la obligación principal que se encuentra sujeta a tributación. ${ }^{15}$.

\section{CONCLUSIONES}

De lo razonado precedentemente, podemos deducir y extraer de forma clara y precisa las siguientes conclusiones:

1. Nuestro ordenamiento jurídico desde la década del 2000 ha ido incorporando nuevos métodos de resolución de conflictos, esto con el fin de descongestionar los tribunales del país, lo que también acerca a las personas a participar en la resolución de los conflictos. Es la tendencia en nuestro ordenamiento jurídico.

2. Esta nueva cultura de la resolución de conflictos se crea a partir de la incorporación de métodos alternativos de resolución de conflictos a los procedimientos de mayor aplicación considerando la cantidad de los procesos que debe soporta nuestro Poder Judicial.

3. Como se ha visto, nuestro ordenamiento jurídico cuenta con instancias en que la mediación es un requisito de admisibilidad de las demandas o bien, como una buena práctica de la ciudadanía, que, aunque no tenga un procedimiento expreso, busca evitar la judicialización del pleito, con sus respectivos gastos.

\footnotetext{
${ }^{14}$ Fallo Tribunal Contencioso de Colombia: Sala de decisión, Tribunal Contencioso Administrativo de Risaralda. Ex. Rad. 66001-23-31-001-2008-00219-01. Nulidad y Restablecimiento. Actor: Vivian Lidia Chujfli Haddad.

${ }^{15}$ Lo anterior, conforme al artículo 20 de la Ley Orgánica de la Procuraduría General de la República de Costa Rica, Decreto N 27514-J, y del artículo 50 del Código de Normas y Procedimientos Tributarios de dicho país.
} 
4. La Ley 20.322 que crea los Tribunales Tributarios y Aduaneros, se ha visto mejorada en el sentido anterior, ya que incorpora a su procedimiento el llamado a conciliación obligatorio con ciertas limitaciones propias emanadas de los tributos como tal, intentando que las partes puedan solucionar colaborativamente sus conflictos, evitando que este llamado sea procedente solo según criterio del juez, como era anteriormente.

5. Los intereses discutidos en tanto se determina la certeza de la obligación tributaria y su exigibilidad, son plenamente disponibles mientras no exista una sentencia firme y ejecutoriada que así lo determine y haga nacer la obligación de pago del contribuyente y en virtud de ello se podrá conciliar a su respecto.

6. En el derecho comparado, especialmente en Estados Unidos, Gran Bretaña, Francia y España, han establecido mecanismos alternativos de solución de controversias; por medio de acuerdos, los que sin duda contribuyen a la rapidez y eficacia en lo que respecta al ámbito tributario.

7. Las modificaciones incorporadas con la ley 21.039 sobre "Fortalecimiento y perfeccionamiento de la justicia tributaria y aduanera” en relación con la conciliación resultan insuficientes para el estándar de los nuevos procedimientos en la justifica chilena.

\section{BIBLIOGRAFÍA.}

CALAMANDREI, Piero, Instituzioni di diritto processuale civile se condo il nuovo códice, (Milán, Editorial Podova, 1943), pp. 209 - 214.

CASANELLAS, M. \& OLAY DE PAZ, M, "La revisión de Actos Administrativos y el Régimen Sancionador Tributario en el Reino Unido", en Quincena Fiscal (No. 12 de 2003).

CASARINO, Mario, Manual de Derecho Procesal. Civil. Tomo VI, (Santiago, Editorial Jurídica, 2005).

CASARINO, Mario, Manual de Derecho Procesal. Civil. Tomo III, (Santiago, Editorial Jurídica, 2005).

COLOMBO, Juan, "La jurisdicción en el Derecho Chileno", en Homenajes Anales de la Facultad de Ciencias Jurídicas y Sociales, Vol. 8 ( $N^{\circ} 8$ de 1968)

JEQUIER LEHUEDÉ, Eduardo. La mediación como alternativa de solución de los conflictos empresariales en Chile: Razones y mecanismos para su regulación. Revista de derecho (Valdivia, 2016), 29(1), 91-118. https://dx.doi.org/10.4067/S071809502016000100005

SISTEMA NACIONAL DE MEDIACIÓN FAMILIAR. ¿Qué es la mediación? Obtenido del sitio: http://www.mediacionchile.cl/sitioumed/trabajadores. (Consultado el día 28/05/2019)

FERREIRO, J.J. "Arbitraje Sobre Relaciones Tributarias", en AA.VV., Convención y Arbitraje en el Derecho Tributario, Madrid, IEF, pp, 263-266. (2016)

GONZALEZ-CUELLAR, M.L., "El arbitraje en el Derecho Tributario", en Estudios Financieros, (N¹67 de 1997), pp. 11-44

GIL, Eva, Las actas con acuerdo en el procedimiento inspector tributarios, (Madrid, Thompson Reuters, 2009).

ARRIETA, MARTINEZ DE PISÓN, Juan, "Derecho Tributario y Medios Alternativos de Solución de Controversia”, en Anuario de la Facultad de Derecho de la Universidad Autónoma de Madrid, (Nº11 de 2007), pp. 11-44. 
PEREZ, BAEZ, Susana: "Arbitraje Tributario: recorrido procesal”, en Cuestiones Jurídicas Revista de Ciencias Jurídicas, Universidad Rafael Undaneta," (Vol. II, N² de 2008), p. 11-26.

ROMERO, M.L: Las actas con acuerdo en la Ley General Tributaria y en el derecho comparado, (Toledo, Ediciones Universidad Castilla de -La Mancha, 2010).

RUAN, SANTOS, Gabriel “El Arbitraje Tributario. ¿Algún Avance?”, en Revista Comité de Arbitraje, 3era edición, pp. 3-5 (2010/2011):

UGALDE, GARCÍA \& UGARTE: Tribunales Tributarios y Aduaneros, 3era Edición, (Santiago, Editorial Legal Publishing, 2009).

EVANS, Eugenio: Los tributos en la Constitución, 2da Edición, págs. 105 - 107 (Santiago, Editorial Jurídica de Chile, 2010)

VARGAS, Manuel, Obligación Civil y Obligación Tributaria, (Santiago, Editorial Jurídica Conosur Ltda, 1995).

VICENTE-ARCHE, Paula, El Arbitraje En El Ordenamiento Tributario Español: una propuesta, (Madrid, Editorial Marcial Pons, 2005). 